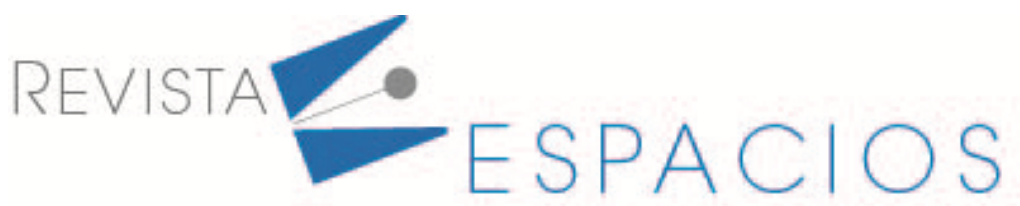

\title{
Impacto social y económico de los factores de riesgo que afectan la seguridad ciudadana en Ecuador
}

\author{
Social and economic impact of risk factors affecting citizen security in Ecuador
}

\begin{abstract}
ORTEGA, Kevin M. ${ }^{1}$
PINO, Sergio L. ${ }^{2}$

\section{Resumen}

El objetivo de la investigación fue determinar el impacto social y económico de los factores de riesgo que afectan la seguridad ciudadana en Ecuador. La metodología usada fue de carácter cuantitativo, los métodos empleados fueron el analítico-sintético y el contable. Entre los resultados mas importantes se encontró que, en promedio, el $42 \%$ de la población hubiera apoyado un golpe de Estado como reacción ante a la inseguridad delincuencial durante el período 2010-2018 y el costo económico y social para Ecuador fue del $3.05 \%$ del PIB en el mismo período.

Palabras clave: impacto socio económico, delincuencia, seguridad ciudadana
\end{abstract}

\begin{abstract}
The objective of the research was to determine the social and economic impact of risk factors that affect citizen security in Ecuador. The methodology used was quantitative, the methods used were analyticalsynthetic and accounting. Among the most important results are that on average $42 \%$ of people would have supported a coup d'état against a lot of crime between 2010-2018; and, the economic and social cost for Ecuador is 3.05\% of GDP.
\end{abstract}

Key words: socioeconomic impact, crime, citizen security

\section{Introducción}

En América Latina, a pesar de que cada país tiene su propio sistema económico y objetivos distintos, comparten un desafío en común, el de consolidar ese crecimiento económico en desarrollo para sus habitantes. Como parte de esos retos, la seguridad constituye quizás el nudo crítico más importante que resolver. De hecho, "América Latina y el Caribe es la región más violenta del mundo, la tasa de homicidios de la región es cinco veces mayor que el promedio mundial " (CEPAL, 2019, pág. 47).

En este contexto, "la inseguridad se ha convertido en un problema para los gobiernos que ven crecer la demanda dirigida hacia ellos, pero que se muestra ineficiente para proveerla, dando paso a la expansión de la seguridad privada" (Arias, 2009, pág. 25). En Ecuador, la seguridad ciudadana ha pasado a ser un nudo crítico, según datos del Ministerio de Gobierno (2019) “la tasa de homicidios pasó de 5.8 por cada 100.000 habitantes en 2018 a 6.1

\footnotetext{
${ }^{1}$ Economista. Facultad de Ciencias Económicas. Universidad de Guayaquil. Ecuador. kevin.ortegaal@ug.edu.ec

2 Docente Investigador. PhD, Economista. Facultad de Ciencias Económicas. Universidad de Guayaquil.Ecuador. sergio.pinop@ug.edu.ec
} 
en 2019, mientras que el número de denuncias por robos pasó de 65.439 a 72.502 delaciones por este delito, en dichos años respectivamente". Lo cual claramente representa un incremento de la inseguridad y con ello de la probabilidad de ser víctima de la delincuencia.

No obstante, con el incremento de los niveles delictivos y de violencia en el Ecuador, también han aumentado el malestar social y la desaprobación hacia el gobierno por parte de la población, ya que perciben al Estado como débil, ineficiente e incapaz de brindar seguridad, lo cual al mismo tiempo ha conllevado a una reconfiguración del tejido social y del orden existente, modificando el modo en el que las personas se relacionan con su entorno. Por otro lado, esto ha contribuido para que las personas exijan penas más fuertes, y en otros casos al no obtener respuesta, han optado por hacerse cargo de su propia seguridad y la de sus casas, llevando a un proceso de desconfianza hacia las instituciones del Estado.

Es por estas razones que, "la seguridad es un bien público y el Estado, en especial sus fuerzas de policía, deben garantizar que el acceso a la seguridad sea justo y equitativamente distribuido" (Abello \& Pearce, 2007, pág. 16). Debido a que la inseguridad, puede afectar el grado de legitimidad que las personas otorgan a sus instituciones, por ello, "el Estado es el único actor que tiene la responsabilidad de asegurar la provisión de la seguridad ciudadana como un bien público" (PNUD, 2013, pág. 111).

Es por ello, que el objetivo de esta investigación fue determinar el impacto social y económico de los factores de riesgo que afectan la seguridad ciudadana en Ecuador. En este sentido, fue preciso estudiar los aportes teóricos que explican cuáles son las causas que originan los comportamientos delictivos en las personas, y en función de aquello analizar los efectos que provoca la inseguridad ciudadana en la sociedad, en términos no monetarios, como percepción de inseguridad, o el nivel de respaldo (rechazo) hacia las instituciones, etc. Además de estimar los costos monetarios que se producen debido al crimen, tales como los gastos en seguridad incurridos por los agentes económicos en Ecuador.

\subsection{Factores de riesgo causales del crimen, violencia y de delincuencia}

De acuerdo con Zambrano (2016) "el concepto de seguridad debe poner mayor énfasis en el desarrollo de políticas públicas de prevención y control de los factores que generan violencia e inseguridad, no simplemente en tareas meramente represivas ante hechos consumados" (pág. 63). Es decir, "identificar los factores de riesgo causales del crimen y la delincuencia es fundamental a efectos de definir y enfocar los programas de prevención" (Tanner, Jo, \& Lipsey, 2019).

\subsubsection{Escuela crítica}

Según esta teoría, el origen de los problemas sociales como la violencia y las conductas socialmente negativas eran fruto del sistema capitalista de aquella época, que había creado una mayor desigualdad entre los grupos sociales, modificando la estructura social y las relaciones entre las personas. "La criminología crítica contextualiza la realidad del comportamiento desviado y pone en evidencia su relación funcional o disfuncional con las estructuras sociales, con el desarrollo de las relaciones de producción y de distribución" (Baratta, 2004).

En primer lugar, "la sociedad está gobernada por una clase dominante, las leyes defienden estos intereses, las penas se aplican de forma desproporcionada a clases inferiores; el delito es resultado de la lucha entre los que tienen y los que carecen de poder" (Larrauri, 2000). En decir, "desde una perspectiva marxista, los órganos de control tienen responsabilidad en la creación de la desviación, sumado a las desigualdades económicas estructurales, propias del capitalismo" (Larrauri, 2000). Aunado a lo anterior, la desigualdad en esa sociedad estaba generando los potenciales grupos delincuenciales, dado que "las máximas posibilidades de ser seleccionados para formar parte de la población criminal aparecen concentradas en los niveles más bajos de la 
escala social, la posición precaria en el mercado de trabajo y defectos de socialización familiar y escolar" (Baratta, 2004).

\subsubsection{Teorías Ecológicas}

Con las investigaciones de académicos de la Universidad de Chicago, tales como Robert Park, el estudio del delito adquiere un nuevo enfoque. La ciudad para Park es entendida como un hábitat en donde se produce una "organización espontánea de la vida, y la población tiende por sí misma a segregarse, en virtud de sus intereses, gustos y temperamentos" (Park, 1999). Por ende, "la influencia del entorno urbano, es responsable del aumento del vicio y la criminalidad; la promiscuidad malsana y contagiosa en la que viven el indigente, el vicioso y el delincuente hace que se reproduzcan indefinidamente" (Park, 1999).

Es decir, la urbe estimula la perdición de las personas porque constituye un espacio de desintegración moral, además, lo que hace atractiva a la ciudad se debe a que tanto "el criminal, el vicioso, e incluso el hombre genial puede encontrar la compañía de afines, de tal suerte que el vicio o el talento, tienen un clima moral para florecer" (Park, 1999). La dinámica comercial y social de las urbes, modificaron las relaciones dentro de la familia causando la ruptura de su autoridad, ya que "con el desarrollo de grandes ciudades (...), las viejas formas de control social como la familia, el vecindario, etc., se han debilitado y su influencia ha ido disminuyendo" (Park, 2016).

Los problemas sociales como la delincuencia tienden a concentrarse en áreas específicas, "los denominados "puntos calientes" o "zonas prohibidas", que tienen varias características estructurales en común, generalmente se concentra en áreas de fuerte desventaja económica, exclusión social y pobreza" (Banco Mundial, 2011, pág. 29). Esta zona era conocida por los ecológicos como un área de deterioro, en el cual se encontraban los estratos sociales más bajos, y en donde la presencia de familias disfuncionales y la delincuencia juvenil era más frecuente.

\subsubsection{Teoría de la Anomia}

Según esta teoría es la ausencia de normas lo que puede conllevar a un estado de detrimento social. No obstante, es importante considerar la influencia de las clases sociales en una sociedad, ante todo porque "una estructura de clases relativamente rígida, un sistema de castas, pueden limitar las oportunidades en una sociedad" (Merton, 1995, pág. 225). En este orden de ideas, la estructura cultural, "consiste en objetivos, propósitos e intereses definidos, sustentados como legítimos por todos los individuos de la sociedad y al mismo tiempo define, regula y controla los modos admisibles de alcanzarlos" (Merton, 1995, pág. 210).

Empero, los estratos sociales más bajos no tienen ni las mismas oportunidades, ni mucho menos los medios para lograr esos fines, entonces se produce una disonancia, porque "la gran importancia cultural dado al éxito pecuniario, más la limitación de la estructura social, genera una tensión hacia prácticas innovadoras que se apartan de los medios institucionales" (Merton, 1995, pág. 228).En consecuencia, los incentivos a delinquir aumentan conforme disminuyen las oportunidades.

En este contexto se produce un estado de anomia, porque "el equilibrio entre los fines culturalmente señalados y los medios se hace muy inestable con la importancia cada vez mayor de alcanzar los fines cargados de prestigio por cualquier medio" (Merton, 1995, pág. 225). En suma, la delincuencia es producto de "la pobreza y las desventajas que los acompañan para competir por los valores culturales aprobados por la sociedad, en este caso, el éxito pecuniario como meta predominante, el resultado normal son altas proporciones de conductas delictuosa" (Merton, 1995, pág. 226).

\subsubsection{Teoría de la Asociación Diferencial}

El estudio de la delincuencia como un mal social, fue afrontado con un matiz diferente por el criminólogo y sociólogo estadounidense Edwin H. Sutherland, en principios de criminología (1947) lo que daría origen a la teoría de la asociación diferencial, en el que ligaba el florecimiento del crimen con patrones de comportamientos que 
son adquiridos por las personas, como resultado de las relaciones sociales; en tal sentido, resumiendo los principios planteados por Sutherland (2016):

El comportamiento delictivo es aprendido en interacción con otras personas (grupos íntimos), el aprendizaje incluye las técnicas de comisión del delito y la dirección específica, esta última es aprendida a partir de definiciones favorables y desfavorables a los códigos legales. Por lo tanto, una persona deviene en delincuente a causa del exceso de definiciones favorables a la violación del derecho; las asociaciones diferenciales pueden variar en frecuencia, duración (págs. 120-121).

En habidas cuentas, lo que señala Sutherland es que la delincuencia es resultante de la interacción entre personas, con sujetos que tienen ciertas conductas erróneas. Entonces, la asociación diferencial que da origen al crimen, depende del grado de exposición de las personas entre los malos y buenos hábitos, y también de la capacidad que tenga el individuo para ir adquiriendo los conocimientos y habilidades, resultantes de la observación y experiencia. Para Sutherland el delito no es exclusivo de una clase social en particular, lo cual lo confirma en su obra "Delito de cuello blanco" publicado en 1949, en el que define al mismo como "un delito cometido por una persona de respetabilidad y status social alto en el curso de su ocupación (...) lo significativo es que no está asociado con la pobreza, o con patologías sociales y personales que acompañan la pobreza" (Sutherland, 1999, pág. 65).

\subsubsection{Crimen y castigo: un enfoque económico}

Según este aporte teórico, el delincuente es un agente racional que evalúa el costo y el beneficio de tomar determinadas decisiones. De esta forma, "una persona comete un delito si la utilidad esperada para él excede la utilidad que podría obtener usando su tiempo (recursos) en otras actividades, por lo tanto, algunas personas se convierten en "criminales", porque sus beneficios y costos difieren" (Becker, 1974, pág. 7). Así pues, para Becker los delincuentes son sujetos racionales que tienden a evaluar, entre las diferentes alternativas, aquella que les permita maximizar su bienestar, es decir, "el delincuente sustituye entre delitos" (Becker, 1974, pág. 8).

Entonces, es en el resultado del balance entre costos e ingresos lo que determina la probabilidad de cometer un delito por parte de las personas, es decir, "cuando el ingreso marginal por delinquir es mayor al costo marginal, la pérdida para los delincuentes se minimiza" (Becker, 1974, pág. 12). Por ello, la administración de justicia debe asegurarse que el delito no reditué, por ejemplo, "un aumento de la probabilidad de ser condenado o del castigo reduciría la utilidad esperada del delito y por lo tanto, el número de delitos, ya que aumentaría la probabilidad de pagar el precio más alto" (Becker, 1974, pág. 8). Por otro lado, "un aumento de los ingresos disponibles en actividades legales o en la observancia de la ley, debido por ejemplo, a la educación, reducirían los incentivos para entrar en actividades ilegales y con ello a los delitos" (Becker, 1974, pág. 8).

\subsection{Delitos que afectan la seguridad ciudadana}

En el apartado anterior se establecieron como factores causales del crimen y la violencia a la desigualdad en la aplicación de la ley, a un entorno de desorganización social, a la desintegración familiar, al desempleo, el no contar con los medios necesarios para alcanzar los fines propuestos, además de la pobreza, y también que la delincuencia era el resultado del aprendizaje producto de las relaciones sociales, la corrupción y finalmente, lo que lleva a las personas a convertirse en delincuentes se debía a que los beneficios obtenidos eran mayores a sus costos. No obstante, es preciso abordar desde una perspectiva general los delitos que afectan la seguridad ciudadana, como plantea (Libreros, 2001):

En todas las sociedades del mundo, con mayor o menor intensidad, el fenómeno de la violencia afecta por igual a todas las personas, quienes como sujetos pasivos se ven expuestos a las embestidas del 
crimen, la delincuencia y los conflictos armados, flagelos que se erigen como los factores de riesgo de la seguridad ciudadana (pág. 206).

\subsubsection{Homicidios}

El homicidio es quizás la consecuencia más grave que puede generar la delincuencia, debido a que, lleva implícita la pérdida irreparable de la vida; de hecho, en el estudio global de homicidios 2019 de la Oficina de las Naciones Unidas contra la Droga y el Delito (UNODC, 2019) se señala que, "el crimen organizado fue responsable del 19\% de los homicidios en 2017 y subraya que, desde el inicio de este siglo, esas agrupaciones delictivas han matado a tanta gente como todos los conflictos armados combinados". Es importante recalcar, que en el estudio realizado por Naciones Unidas, también se menciona que los hombres jóvenes son al mismo tiempo las víctimas y los victimarios en lo corresponde a los homicidios, además "la probabilidad de que un niño sea asesinado aumenta junto con su edad en todas las regiones y marca el periodo entre los 15 y los 29 años como el de mayor riesgo de homicidio a nivel mundial" (UNODC, 2019).

El fenómeno de violencia, ha pasado a ser una característica identificadora de América Latina y el Caribe pues "es la región más violenta del mundo, la tasa de homicidios de la región es cinco veces mayor que el promedio mundial (22,1 homicidios y 4,4 homicidios por cada 100.000 personas, respectivamente)" (CEPAL, 2019, pág. 47). El problema de la seguridad en Ecuador comparte características comunes que tienen los países latinoamericanos, la debilidad de sus marcos legales y la ineficacia de sus autoridades para identificar los potenciales delincuentes, han contribuido para que grupos criminales aprovechen la fragilidad de la ley, como una oportunidad para cometer delitos y paralelamente ganar impunidad.

El sicariato en Ecuador constituye un ejemplo para ilustrar lo anterior, "la gran mayoría de involucrados que cometen sicariatos son adolescentes, por su situación de vulnerabilidad son el blanco perfecto para aquellos grupos delictivos, y además el COIP no establece sanciones específicas para aquellos adolescentes directamente involucrados en sicariatos" (Noboa, Ruiz, Pazmiño, \& Vela, 2019, pág. 56). Asimismo, "las provincias con mayor índice de casos de sicariato donde se encuentran involucrados adolescentes son Guayas, Manabí, El Oro, Esmeraldas y Sucumbíos" (Noboa et al., 2019, pág. 48).

Tabla 1

Muertes violentes entre 2019 y septiembre de 2021 (Ecuador)

\begin{tabular}{lc}
\hline Año & $\begin{array}{c}\text { Muertes } \\
\text { violentas }\end{array}$ \\
\hline 2019 & 1187 \\
2020 & 1372 \\
2021 septiembre & 1753 \\
\hline
\end{tabular}

Fuente: Ministerio de Gobierno

La mayor cantidad de fallecidos es resultado de la violencia criminal, en 2019 se registraron 665 muertes por ese tipo de violencia, mientras que en 2020, se cometieron 771 homicidios, lo que representa el $56 \%$ del total de muestras violentas (tabla 1). Por otra parte, en base a datos de la misma institución, hasta septiembre de 2021, se perpetraron 1310 homicidios que represente el $75 \%$ de la cifra total de muertes violentas (1753 hasta septiembre de 2021).

Los datos mostrados anteriormente sirven para develar el estado alarmante de la seguridad del país. Esto ha generado que las personas ya no se sientan seguras en el espacio en que viven o trabajan produciéndose así desconfianza hacia sus semejantes.

En lo que respecta a este tipo de delitos, "los delincuentes estarán interesados en objetivos a los que les atribuyen valor" (Felson \& Clarke, 2019, pág. 63). Lo que significa que los factores motivacionales detrás del 
crimen se asocian a las características de las víctimas u objetos del robo, entonces, es de esperarse que el delincuente analice su víctima potencial y en función de los recursos que posea la misma tome la decisión de cometer el delito, es decir, la capacidad económica del individuo se erige como un elemento decisor para el delincuente.

No obstante, "ha habido un proceso de evolución desde un tipo de delito tradicional, como el robo en pequeña escala, hacia un tipo de delito más violento como son los robos y asaltos, que incluye sustracción de vehículos y en domicilios" (Arcos, Carrión Mena, \& Palomeque, 2003, pág. 103). Por ejemplo, "en Quito, los vehículos son robados mayoritariamente cuando están estacionados, sin presencia de ocupantes; mientras en Guayaquil, por el contrario, el hecho se suscita en presencia de usuarios y con uso de armas de fuego" (Abril \& Tupiza, 2008, pág. 77).

El aumento de la delincuencia ha creado un sistema de mercado ilegal para los bienes robados, lo cual "implica niveles de organización de la actividad delictiva, con circuitos de mercado negro por donde circulan los bienes robados" (Arcos et al., 2003, pág. 103). De esta forma, el crimen crea su propio mercado que tiende a crecer en función de lo robado, en otras palabras, los delincuentes para minimizar sus costos, han sabido encontrar otras maneras de obtener beneficios.

\subsubsection{Drogas}

El narcotráfico en Ecuador es un tema complejo. Si bien es cierto no existen datos que lo señalen como productor de algún tipo de droga, se encuentra en una posición crítica debido a su ubicación geográfica y también por la falta de eficacia en el control por parte del Estado. En tal sentido, vale indicar que "Ecuador es un país de tránsito para las drogas, provenientes de Colombia (cocaína- heroína) y Perú (cocaína), que tienen como destino a EEUU y Europa. Es también un país de tránsito de precursores químicos para producir drogas" (United States Department of State, 2020, pág. 138).

Por otro lado, con la legalización del consumo de droga en pequeñas cantidades, han convertido al país en un mercado magnífico para dicho negocio, en especial en ciertas zonas de gran actividad económica, ya que son lugares donde la droga puede encontrar su mercado o los delincuentes el suyo, como un medio para tener los recursos de forma ilegítima para su consumo, lo que ha generado, al mismo tiempo, el aumento de la inseguridad en las calles, en especial, debido a robos y también el incremento de la cifra de homicidios asociados principalmente a grupos delincuenciales que se dedican a ese tipo de actividades ilegales; no obstante, las consecuencias han trascendido hasta las instituciones educativas.

En virtud de lo anterior, el consumo de las drogas ha invadido los centros de estudio, "la drogadicción en adolescentes, constituye un problema apremiante para la educación ecuatoriana en varios centros educativos" (Loor, Hidalgo, Macías, García, \& Scrich, 2018, pág. 130). Entre los factores facilitadores del consumo de drogas están "la disfunción familiar, las influencias del entorno y el desconocimiento de los efectos e las drogas para la salud" (Loor et al., 2018, pág. 130).

\subsection{Impactos del deterioro de la seguridad ciudadana}

\subsubsection{A nivel social}

Percepción de inseguridad

El crimen y la violencia en un país no sólo generan efectos negativos sobre las víctimas directas de la delincuencia, sino que además sus consecuencias trascienden y se reflejan en toda la sociedad. En esta perspectiva, la delincuencia puede resentir los vínculos afectivos entre las personas, ya que, "la pérdida de la seguridad genera efectos con potencialidad de riesgo de enfermedad, así como de producir afectaciones en las relaciones 
interpersonales, que se ven teñidas por la desconfianza y la incertidumbre" (Vuanello, 2009, pág. 36). Esto significa que la delincuencia puede dejar en sus víctimas secuelas profundas, caracterizadas por la restricción en la interacción entre personas, además de que pueden tender a atravesar periodos de angustia y nerviosismo ante la posibilidad de sufrir experiencias futuras de este tipo.

Para Robles (2014) "las condiciones sociales son las productoras de los miedos de las personas como parte de los hechos violentos a los cuales nos enfrentamos a diario; creando imaginarios sociales de inseguridad y desconfianza del otro" (pág. 98). Este miedo de volver a ser víctima de la delincuencia puede manifestarse de muchas formas a nivel social, por ejemplo, las personas dejan de transitar por determinados lugares o dejan de salir a ciertas horas, evitando así entornos hostiles; además, cabe considerar que a nivel personal los sujetos pueden pasar a un estado de autoaislamiento como un medio de autoprotección, en suma, los individuos cambian su cotidianidad.

Pérdida de capital social

De acuerdo con Lunecke \& Ruiz (2007) "el aumento de la criminalidad y la violencia erosiona el capital social y el control social por parte de la comunidad, debilitando los lazos y vínculos entre las personas" (pág. 242). Por ende, los efectos perjudiciales del crimen sobre el capital social, se reflejan en el debilitamiento de la cohesión social dentro de una colectividad ya que el grado de confianza por parte de los ciudadanos hacia sus semejantes disminuye, y además, cuando se rompen todo tipo de relaciones entre vecinos se generan zonas aisladas o desconectadas entre sí.

En consecuencia, se genera el escenario propicio para la apropiación del espacio público por parte de actores ilegales, sea dentro un barrio o zonas de una ciudad, ya que se restringen las relaciones sociales entre vecinos, con lo cual la acción social comunitaria frente la delincuencia pierde valor, la armonía pasada del barrio o lugar de residencia se transforma en un ambiente hostil, es decir, "la ausencia de capital social puede hacer que una sociedad sea vulnerable a la explotación por grupos de la delincuencia organizada” (UNODC, 2012, pág. 136).

Cabe recalcar que la fragmentación del capital social "crea desconfianza, falta de interés en la asociatividad, generando un capital social negativo (incremento de la delincuencia, impunidad, crimen organizado, corrupción, alcoholismo, etc." (Rivera, 2016, pág. 129). En otras palabras, el deterioro del capital social puede presionar a que se establezcan grupos delincuenciales dentro de los mismos barrios, con poder y autoridad propia, formándose así fronteras invisibles en donde las instituciones de control no pueden ingresar pero la pobreza y la delincuencia son huéspedes permanentes dentro de esos lugares. La ausencia de capital social o su debilitamiento produce un efecto en espiral, pues sus impactos trascienden mucho más allá de las personas, "el conflicto tiene un efecto negativo sobre el capital social de las naciones, pues daña las normas, valores y los vínculos sociales, tanto de escalera, puente o unión, lo que tendrá un impacto negativo en el desarrollo económico y social" (Carrión, 2012, pág. 148).

Pérdida de vidas humanas y pobreza

La consecuencia más grave que produce la delincuencia y/o violencia en un país, es sin duda la muerte de personas, no obstante "el impacto del homicidio doloso va más allá de la pérdida de vidas humanas y puede generar un entorno de miedo e incertidumbre" (UNODC, 2013, pág. 1). Los homicidios resultantes de la delincuencia generan pérdidas sociales y, por un lado, crece el miedo a ser la próxima víctima. Cuando se suscita la muerte de una persona fruto del crimen, la sociedad, la familia y el país pierden. En primer lugar, con el fallecimiento de personas se generan lógicamente años de vida perdidos, pero paralelamente afecta a la esperanza de vida del país, lo cual tiene un impacto aún mayor si las víctimas pertenecen a grupos de poblaciones 
jóvenes, con lo cual también se pierdan años de vida productivos, además de reducirce el bono demográfico al aumentar el número de fallecidos jóvenes.

Es necesario conocer los efectos colaterales en las víctimas indirectas, es decir, aquellas que son familiares de la víctima, como lo sostiene el PNUD (2019) “incluso los hogares que disfrutan de una situación relativamente acomodada pueden caer por debajo de la línea de pobreza si sufren problemas personales (problemas de salud graves) o comunitarios (como la desaparición de la principal fuente de empleo)" (pág. 80). Por ende, cuando el fallecido es el sustento del hogar puede inducir a un estado de pobreza a una familia, motivado por el grado de dependencia económica pasado del cual los familiares de la víctima dependían.

Migración forzada por inseguridad

Es importante considerar los efectos potenciales de los conflictos internos, ya que, "la violencia, es decir, los contextos sociales con elevada conflictividad e inseguridad han llegado a motivar flujos desesperados de migración, particularmente en Centroamérica y México" (Maldonado, Martínez Pizarro, \& Martínez, 2018). La inseguridad también ha llevado al cambio de la composición poblacional de las personas en sus países, dado que el desplazamiento interno constituye una salida en busqueda de espacios con mejor seguridad.

El Alto Comisionado de las Naciones Unidas para los Refugiados-ACNUR (2017) enfatiza que "la inseguridad también está obligando a un número creciente de personas a huir de sus hogares y buscar protección internacional, principalmente en países fronterizos y vecinos" (pág. 1). Es decir, la seguridad es vista como aquella condición necesaria para el desarrollo de la vida, entonces "la posibilidad de llevar a cabo un proyecto de vida libre de violencia y un nivel básico de bienestar y seguridad en el país de origen es central en lo que se conoce como el derecho a no migrar" (Maldonado et al., 2018, pág. 37).

\subsubsection{A nivel institucional}

La inseguridad puede afectar el grado de legitimidad que las personas otorgan a sus instituciones, lo que significa que, "la inseguridad ciudadana y el temor deterioran el apoyo a las instituciones democráticas (...), es decir, la repercusión política es el debilitamiento del Estado y su legalidad" (OEA-PNUD, 2010, págs. 185-186). Desde esta perspectiva, la seguridad se convierte en un eje fundamental para el mantenimiento del orden democrático y la convivencia armónica de los ciudadanos.

En este sentido se comprende que, si un Gobierno a través de sus instituciones no puede garantizar la seguridad que necesitan sus habitantes, se percibe como un Estado frágil, y "un Estado vulnerable, pierde su gobernabilidad democrática cuando la ciudadanía posee reducidos niveles de confianza en las agencias de seguridad (justicia), constituyéndose en terreno fértil para el fomento del miedo y descohesión social, traduciéndose en un ambiente de inseguridad" (Pazinato, 2020, pág. 115).

No obstante, "los niveles de desconfianza se deben no sólo a la ineficiencia sino también a la vinculación de agentes policiales con hechos delictivos y actos de corrupción asociados a las instituciones encargadas de la justicia y la seguridad" (Arias, 2009, pág. 133). Entonces resulta lógico señalar que cuando los representantes de las entidades públicas responsables de la seguridad y justicia se corrompen, el poder del gobierno se deslegitima, más aún si se da en las altas esferas del mismo, lo que invita a la desobediencia civil a la ley y autoridad o a la normalización y recreación de esas mismas prácticas por parte de los ciudadanos.

Sector de la seguridad privada

La inseguridad está produciendo el deterioro de la imagen de las instituciones del Estado, estimulando el desarrollo de la seguridad privada, debido a que, "el crecimiento de la industria de la seguridad armada ha estado en línea con el aumento de la violencia en mucho países de América Latina y el Caribe" (Pérez \& Navarrete, 2018, 
pág. 15). En esa misma línea cabe agregar que otras de las razones que permiten explicar la expansión de este sector están en "el aumento de la delincuencia y el temor que esta inspira, la falta de capacidad de la policía pública para prestar ciertos servicios que la gente y las organizaciones exigen" (UNODC, 2014, pág. 1).

En otros casos, suele estar vinculada con "la frecuencia de los actos de corrupción en que incurren las policías, lo cual impacta positivamente en el crecimiento de la demanda por seguridad privada" (Arias, 2009, pág. 133). La corrupción e ineficiencia por parte de las instituciones del poder político en un país no le permite al Estado hacer uso pleno del monopolio de la violencia considerada legítima, ante esta situación el Gobierno opta por abrirles las puertas a la seguridad privada, y con ello a la privatización del bien público "seguridad ciudadana".

Es decir, que el Estado ante la imposibilidad de satisfacer la demanda social de seguridad, y en respuesta para obtener mayor seguridad ha generado un efecto sustitución de la seguridad pública hacia la privada, pero "el crecimiento de la seguridad privada genera dos riesgos importantes, uno de exclusión social cuando no todos tienen la misma capacidad económica para contratarlos, y el otro, del riesgo de la extralimitación en sus potestades cuando no se tienen adecuadas capacidades regulatorias" (PNUD, 2020, pág. 23).

\subsubsection{A nivel económico}

Los efectos ocasionados por el crimen pueden ser múltiples e inter-dimensionales, debido a que puede afectar al comercio, el emprendimiento y en general, al mundo empresarial y de negocios. Un clima inseguro ocasiona que se enfrenten al costo de oportunidad, de elegir entre realizar alguna mejora en la capacidad productiva del negocio o invertir una mayor cantidad de recursos para mejorar la seguridad del mismo. En otros casos, pueden cambiar los incentivos a realizar actividades económicas licitas por aquellas que están fuera de la ley.

En efecto, "los empresarios y el sector privado han modificado sus conductas debido a la violencia. En casos extremos, los empresarios, especialmente los más pequeños, pueden pasar a la informalidad u ocultar sus ganancias para atraer menos a los criminales" (PNUD, 2013, pág. 96). La inseguridad suele tener un impacto mayor cuando afecta a las microempresas y pequeñas empresas, ya que se enfrentan ante el dilema de asumir el costo de seguridad (menor rentabilidad), o de trasladar ese costo a sus clientes, enfrentándose a la posibilidad de perder clientela o incluso de cerrar el negocio.

Es decir, para las empresas "implica un aumento de los costos de producción debido al gasto en seguridad, primas de seguros, pagos por extorsión y sistemas de protección pasiva, incide también en las posibilidades de conservar las ganancias, y la acumulación de factores productivos" (Giménez, 2007). En virtud de lo anterior, "la delincuencia impacta negativamente en la rentabilidad de las empresas en la medida que desvían recursos a la prevención de la inseguridad que en condiciones "normales" se pudieran dedicar a ofrecer productos a precios más accesibles" (Soria, 2017, pág. 39).

En escenarios en los cuales la seguridad para las compañías se convierte en una necesidad, los negocios incurren en un costo de oportunidad, es decir, "a veces, las empresas se abstienen de ampliar sus operaciones aunque tengan recursos y existan oportunidades de mercado" (PNUD, 2013, pág. 97). Por otro lado, las pérdidas que sufren los negocios por constantes robos, contribuyen a generar una mala imagen para las compañías ya que las personas cambiarán sus hábitos de compras y tenderán a buscar nuevos establecimientos donde le ofrezcan mejor seguridad. Esto se hará mucho más notorio si las víctimas de robos son los clientes, porque a través de ellos, indirectamente, se habrá estimulado una campaña propagandística negativa y aquello repercutirá en el nivel de ventas y por ende en la rentabilidad de los negocios.

Cabe acotar que "en países donde la corrupción y el crimen han penetrado en las instituciones del Estado, los empresarios temen que los delincuentes accedan a información confidencial de sus empresas para efectos de extorsión" (PNUD, 2013, pág. 96). Ante situaciones como estas, las empresas pierden la seguridad jurídica y con 
ello los incentivos a realizar actividades productivas, lo que acabará afectando al empleo. La delincuencia puede afectar la inversión, sea extranjera o nacional, debido a que un país donde la delincuencia rebasa al Estado, se percibe como un país poco atractivo para realizar inversiones. "A nivel internacional, el desprestigio de un país en el que su Estado se ve rebasado por la delincuencia, en donde no termina de imperar la ley, pierde su atractivo como destino tanto de capitales como de personas" (Hernández \& Narro, 2010, pág. 270).

\section{Metodología}

Para determinar el impacto social y económico de los factores de riesgo que afectan la seguridad ciudadana en Ecuador, durante el período comprendido entre los años 2010-2020, se utilizaron como guías de la investigación los métodos analítico y sintético, debido a que se partió "de la descomposición del objeto de estudio en cada una de sus partes para estudiarlas en forma individual (análisis) y luego se integran esas partes para estudiarlas de manera holística e integral (síntesis)" (Bernal, 2010, pág. 60).

En este sentido, la primera parte de la investigación correspondió a identificar la relación entre los factores precipitantes de delitos (pobreza, desigualdad, tasa de desempleo, tasa de desempleo por edades 15 y 24 años) y el crimen (homicidios intencionales); utilizando datos semestrales para el periodo en análisis. La segunda parte concernió a analizar los efectos que generaba la delincuencia en la sociedad.

Finalmente, para la estimación del costo social y económico de la seguridad ciudadana en Ecuador, se adaptó la metodología utilizada por el BID en la investigación "Los costos del crimen y de la violencia: Nueva evidencia y hallazgos en América Latina y el Caribe", la cual utiliza el método contable puesto que "cuantifica los costos incurridos y las pérdidas experimentadas en las economías que no se observan en ausencia del crimen y luego los utiliza para representar las pérdidas directas de bienestar para los ciudadanos" (BID, 2017, pág. 3)

\section{Resultados y discusión}

\subsection{Correlación entre los factores precipitantes de delitos y el crimen}

En la tabla 2 se observa que la relación entre las variables sociales y los homicidios es directa, no obstante, el mayor grado de correlación se encontraría entre la pobreza por ingresos y la cifra de homicidios con el $90 \%$, seguido de los niveles de desigualdad con el $77,62 \%$. Sin embargo, a pesar de que la correlación entre el desempleo y los homicidios es positiva, la relación es menos fuerte al ser del 34\%. Pero, al realizar la correlación entre la tasa de desempleo más alta por edades (15 y 24 años) con los homicidios, el nivel de correlación es mucho más fuerte (63\%), por lo tanto, cuando aumente el desempleo en este grupo de edades al mismo tiempo se incrementarán los asesinatos.

Tabla 2

Correlación entre las

variables sociales y el crimen

\begin{tabular}{cc}
\hline Variables sociales & Variable crimen (homicidios) \\
\hline Índice de Gini & 0,776260527 \\
\hline Pobreza por ingresos & 0,900955406 \\
\hline Desempleo & 0,346640984 \\
\hline $\begin{array}{c}\text { Desempleo por edades } \\
\text { (15-24 años) }\end{array}$ & 0,6312915 \\
\hline
\end{tabular}

Fuente: Elaboración propia 


\subsection{Percepción de inseguridad}

La figura 1 muestra que para el año 2010, en promedio, un 47\% de personas sentían temor ante la posibilidad de ser víctima de la delincuencia; no obstante, para el año 2012 y 2014 dicha percepción disminuyó al situarse en $44 \%$ y $40 \%$ respectivamente. Para el año 2016 se evidencia un incremento significativo de la inseguridad por parte de las personas al situarse en 49,5\%, mientras que en 2018, 5 de cada 10 personas sentía temor ante un eventual hecho delictivo en su contra, la percepción promedio de inseguridad entre 2010 y 2018 es del $45 \%$.

Figura 1

Percepción de inseguridad, período 2010-2018

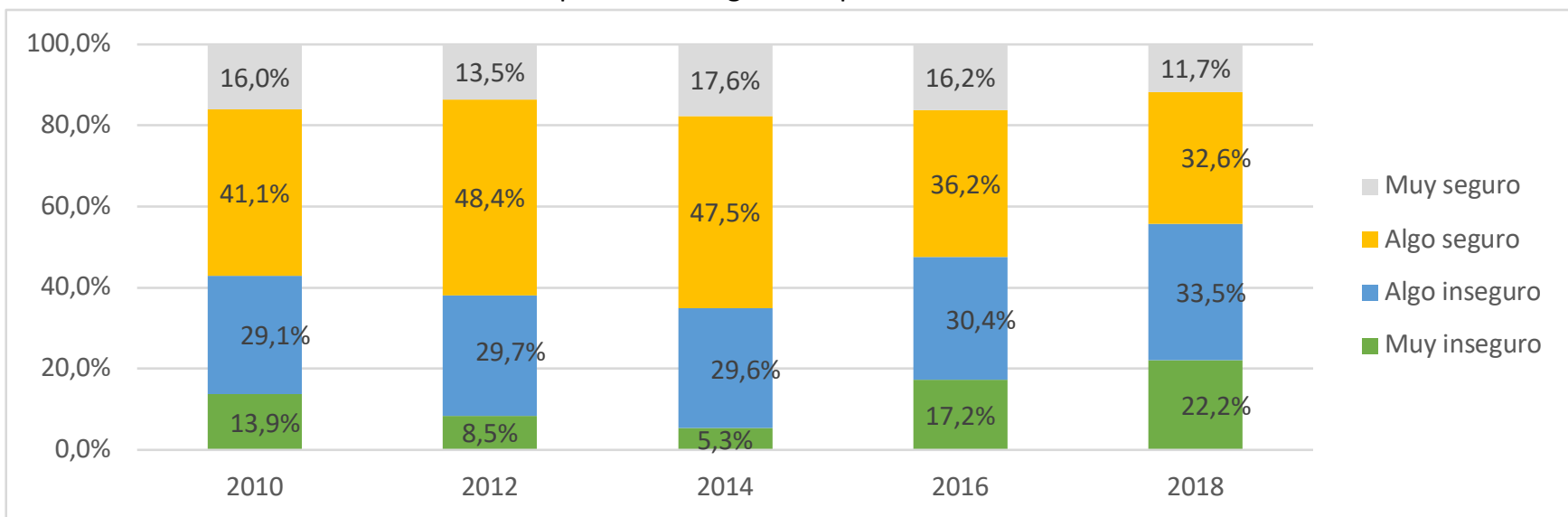

Fuente: Barómetro de las Américas por el Proyecto de Opinión Pública de América Latina (LAPOP)

\subsection{Confianza en la justicia}

La figura 2 muestra el porcentaje de personas que confiaban en que el sistema de justicia castigaría a los culpables, el cual aumentó considerablemente en estos años, ya que en promedio, para el año 2010 el nivel de confianza en que la justicia castigue a los culpables era del 30,5\%, en los años 2012 y 2014 se acrecentó ampliamente con 41,6\% y 47, 7\% respectivamente, llegando a su punto máximo en 2016 con 52,58\%, no obstante, para el año 2018 se presentó una reducción significativa de alrededor de 8,68\%, al situarse en 43,9\%.

\section{Figura 2}

Confianza en que el Sistema Judicial castigue a los culpables

\begin{tabular}{|c|c|c|c|c|c|c|}
\hline \multirow{2}{*}{$100 \%$} & & & \multirow{3}{*}{$15,9 \%$} & & & \\
\hline & $9,8 \%$ & $10,8 \%$ & & \multirow{3}{*}{$28,4 \%$} & \multirow{2}{*}{$21,9 \%$} & \multirow{4}{*}{ Mucho } \\
\hline $80 \%$ & \multirow{2}{*}{$16,6 \%$} & \multirow{3}{*}{$29,8 \%$} & & & & \\
\hline $70 \%$ & & & \multirow{2}{*}{$29,2 \%$} & & \multirow{2}{*}{$16,6 \%$} & \\
\hline $60 \%$ & \multirow{2}{*}{$29,0 \%$} & & & \multirow{2}{*}{$23,7 \%$} & & \\
\hline $50 \%$ & & \multirow{4}{*}{$32,9 \%$} & \multirow{4}{*}{$36,9 \%$} & & \multirow{3}{*}{$32,7 \%$} & \multirow{4}{*}{$\begin{array}{l}\text { Algo } \\
\text { Poco } \\
\text { Nada }\end{array}$} \\
\hline $40 \%$ & \multirow{4}{*}{$44,7 \%$} & & & \multirow{3}{*}{$25,0 \%$} & & \\
\hline $30 \%$ & & & & & & \\
\hline $20 \%$ & & & & & \multirow{3}{*}{$28,7 \%$} & \\
\hline \multirow{3}{*}{$\begin{array}{r}10 \% \\
0 \%\end{array}$} & & $26,5 \%$ & \multirow{2}{*}{$18,0 \%$} & \multirow[t]{2}{*}{$22,8 \%$} & & \\
\hline & & & & & & \\
\hline & 2010 & 2012 & 2014 & 2016 & 2018 & \\
\hline
\end{tabular}

Fuente: Barómetro de las Américas por el

Proyecto de Opinión Pública de América Latina (LAPOP) 


\subsection{Golpe de Estado por excesiva delincuencia}

En la figura 3 se observa que el respaldo al poder público por parte de las personas llegó a su punto más alto en 2014, ya que $71,6 \%$ de los ecuatorianos no hubiesen dado apoyo a un Golpe de Estado en ese año. Sin embargo, en 2016 el porcentaje de personas que no estaría de acuerdo con el derrocamiento del Gobierno se reduce en alrededor del $11,4 \%$. Esta tendencia se acentúa en 2018 , cuando solo el $49,6 \%$ no respaldaría dicha acción, lo que significa que 5 de cada 10 personas apoyaría el Golpe de Estado; en promedio entre 2010-2018 el $42 \%$ de las personas aprobaría que los militares asuman el poder.

Figura 3

Golpe de Estado justificado por militares, frente a mucha delincuencia

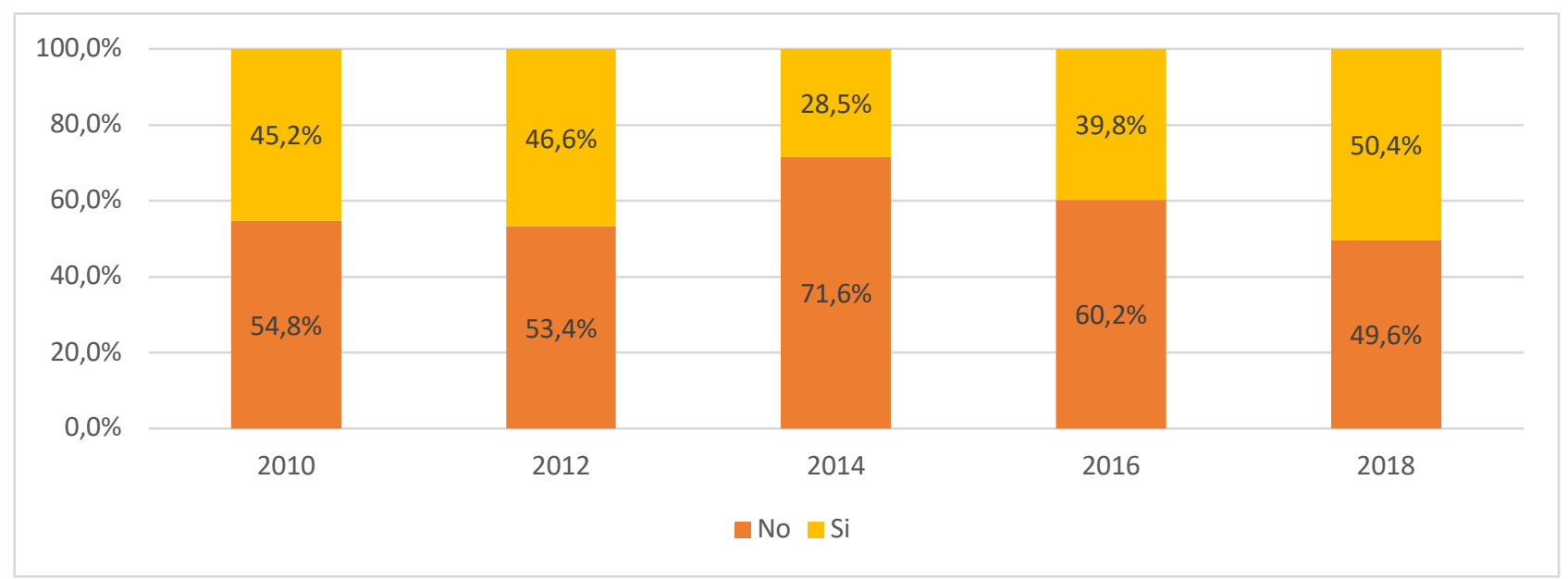

Fuente: Barómetro de las Américas por el Proyecto de Opinión Pública de América Latina (LAPOP)

\subsection{Costo social por homicidios y de la población carcelaria}

La tabla 3 ilustra los costos sociales correspondientes a los homicidios y a la población carcelaria, para los años 2010-2020. En este sentido, en 2010 se registró el ingreso perdido más alto por homicidios del periodo considerado en este estudio, el cual fue de $\$ 21$ millones. El costo social por homicidios fue de $\$ 140$ millones entre 2010-2020. Por otra parte, la población carcelaria registró un crecimiento promedio del 9.26\% entre 20102020. Los ingresos no generados por la población delictiva llegaron a un máximo de \$12,8 millones en 2019. Los ingresos totales perdidos por la población penitenciaría fue de $\$ 102$ millones. El total de los costos sociales es de $\$ 242.307 .862$, entre 2010-2020. Es decir, los costos producidos por la delincuencia y/o violencia en la sociedad son mayores en relación a lo que pierden los presidiarios.

Tabla 3

Costos sociales

\begin{tabular}{|c|c|c|c|c|c|c|c|}
\hline Año & $\begin{array}{c}\text { Homicidios } \\
\text { Intencionales }\end{array}$ & $\begin{array}{l}\text { TOTAL } \\
\text { AVPP* }\end{array}$ & \multicolumn{2}{|c|}{$\begin{array}{l}\text { Ingreso perdido por } \\
\text { homicidios }\end{array}$} & $\begin{array}{l}\text { Población } \\
\text { carcelaria }\end{array}$ & \multicolumn{2}{|c|}{$\begin{array}{l}\text { Ingresos no } \\
\text { generados }\end{array}$} \\
\hline 2010 & 2.605 & 71.237 & $\$$ & $21.919 .632,08$ & 14.550 & $\$$ & 4.477 .035 \\
\hline 2011 & 2.325 & 63.379 & $\$$ & $19.444 .552,40$ & 16.704 & $\$$ & 5.124 .787 \\
\hline 2012 & 1.911 & 50.423 & $\$$ & $16.155 .530,93$ & 20.826 & $\$$ & 6.672 .650 \\
\hline 2013 & 1.710 & 45.553 & $\$$ & $16.062 .108,07$ & 24.863 & $\$$ & 8.766 .694 \\
\hline 2014 & 1.296 & 34.372 & $\$$ & $12.098 .879,94$ & 23.531 & $\$$ & 8.282 .912 \\
\hline 2015 & 1.037 & 26.800 & $\$$ & $9.530 .241,67$ & 26.421 & $\$$ & 9.395 .308 \\
\hline 2016 & 941 & 24.395 & $\$$ & $8.223 .508,09$ & 30.656 & $\$$ & 10.334 .138 \\
\hline 2017 & 955 & 24.568 & $\$$ & $8.382 .693,43$ & 35.967 & $\$$ & 12.271 .940 \\
\hline
\end{tabular}




\begin{tabular}{cccccccc}
\hline Año & $\begin{array}{c}\text { Homicidios } \\
\text { Intencionales }\end{array}$ & $\begin{array}{c}\text { TOTAL } \\
\text { AVPP* }\end{array}$ & $\begin{array}{c}\text { Ingreso perdido por } \\
\text { homicidios }\end{array}$ & $\begin{array}{c}\text { Población } \\
\text { carcelaria }\end{array}$ & $\begin{array}{c}\text { Ingresos no } \\
\text { generados }\end{array}$ \\
\hline 2018 & 975 & 25.119 & $\mathbf{\$}$ & $8.377 .128,23$ & 37.802 & $\$$ & 12.606 .967 \\
\hline 2019 & 1.169 & 30.154 & $\mathbf{\$}$ & $9.821 .198,67$ & 39.569 & $\$$ & 12.887 .623 \\
\hline 2020 & 1.353 & 34.837 & $\mathbf{\$}$ & $10.193 .189,38$ & 38.548 & $\$$ & 11.279 .145 \\
\hline Total & $\mathbf{1 6 . 2 7 7}$ & $\mathbf{4 3 0 . 8 3 7}$ & $\mathbf{\$} \mathbf{1 4 0 . 2 0 8 . 6 6 2 , 9 0}$ & & $\mathbf{1 0 2 . 0 9 9 . 1 9 9}$ \\
\hline
\end{tabular}

*Nota: Número de Años de Vida Potencialmente Perdidos (AVPP).

Fuente: DINASED-Ministerio de Gobierno (Homicidios), SNAI (pablación penitenciaria), periodo 2010-2020

\subsection{Costos en prevención para el sector privado}

En la tabla 4 se ilustra el nivel de ingresos para las empresas del sector de la seguridad privada. El promedio de ventas para las empresas de seguridad privada es de $\$ 778$ millones, con un crecimiento del 6,16\% en dicho período. En lo que respecta a las ventas para las empresas de sistemas de seguridad, los ingresos para estas empresas disminuyeron en 3,38\% entre 2010-2019, su nivel promedio de ventas fue de \$62 millones entre 20102019. El servicio con mayor demanda del periodo corresponde a las actividades de seguridad privada con un ingrso total de $\$ 7.780 .328 .104$, mientras que las empresas que prestan servicios en sistemas de seguridad el ingreso fue de $\$ 620.084 .660$, dando un total de ingresos para el sector de $\$ 8.400 .412 .764$ entre 2010-2019. En otras palabras, la preferencia de las personas se dirige hacia servicios por concepto de escolta- guardias, transporte de seguridad blindado, etc. con relación a la instalación de sistemas de seguridad, como alarmas, cámaras, etc.

Tabla 4

Ventas del sector de la seguridad privada

\begin{tabular}{|c|c|c|c|c|c|c|}
\hline \multirow{2}{*}{$\begin{array}{l}\text { Año } \\
2010\end{array}$} & \multicolumn{2}{|c|}{$\begin{array}{l}\text { Actividades de seguridad } \\
\text { privada }\end{array}$} & \multicolumn{2}{|c|}{$\begin{array}{l}\text { Actividades de servicios de } \\
\text { sistemas de seguridad }\end{array}$} & \multicolumn{2}{|c|}{$\begin{array}{c}\text { Total gastos en servicios de } \\
\text { seguridad }\end{array}$} \\
\hline & $\$$ & 480.341 .150 & $\$$ & 75.997 .735 & $\$$ & 556.340 .895 \\
\hline 2011 & $\$$ & 586.628 .338 & $\$$ & 75.580 .628 & $\$$ & 662.210 .977 \\
\hline 2012 & $\$$ & 694.913 .289 & $\$$ & 64.196.715 & $\$$ & 759.112 .016 \\
\hline 2013 & $\$$ & 806.598 .709 & $\$$ & 65.566 .591 & $\$$ & 872.167 .313 \\
\hline 2014 & $\$$ & 879.171 .550 & $\$$ & 67.483.194 & $\$$ & 946.656 .758 \\
\hline 2015 & $\$$ & 914.199.652 & $\$$ & 61.157 .266 & $\$$ & 975.358 .933 \\
\hline 2016 & $\$$ & 829.439 .468 & $\$$ & 51.492 .698 & $\$$ & 880.934 .182 \\
\hline 2017 & $\$$ & 824.231.071 & $\$$ & 52.983 .349 & $\$$ & 877.216 .437 \\
\hline 2018 & $\$$ & 891.322 .802 & $\$$ & 51.767 .273 & $\$$ & 943.092 .093 \\
\hline 2019 & $\$$ & 873.482 .075 & $\$$ & 53.859 .211 & $\$$ & 927.343 .305 \\
\hline
\end{tabular}

Fuente: Directorio de Empresas y Establecimientos (DIEE)-INEC

\subsection{Costos para el Estado}

El gasto en seguridad interna (tabla 5) registró un crecimiento del 8,23\%, entre 2010-2014, siendo el año 2014 el del gasto más alto de la serie con $\$ 1.656$ millones. En promedio entre 2010 y 2020 se gastaron de $\$ 1.525$ millones en seguridad interna. El caso de las instituciones judiciales es diferente, ya que entre 2010 y 2013 el gasto aumento en $7,97 \%$, alrededor de $\$ 396.6$ millones, pero para el resto de años el gasto se redujo en $\$ 158,7$ millones para 2014- 2020, lo que significa una disminución en términos relativos de 3,65\% entre estos años, el gasto promedio en justicia es de $\$ 572,7$ millones entre 2010 y 2020 . En definitiva, la mayor parte del gasto público del Estado (Gobierno) corresponde a seguridad interna, con $\$ 16.373 .591 .155$, mientras que el gasto en el sistema judicial es de $\$ 6.261 .495 .643$. El gasto total fue de $\$ 22.635 .086 .798$ para el período en análisis. 
Tabla 5

Gasto del Estado en

seguridad y justicia

\begin{tabular}{ccccccc}
\hline Año & $\begin{array}{c}\text { Gasto en Seguridad } \\
\text { interna }\end{array}$ & \multicolumn{2}{c}{ Sistema Judicial } & \multicolumn{2}{c}{ Gasto Total } \\
\hline 2010 & $\$$ & 1.115 .938 .380 & $\$$ & 299.010 .196 & $\$$ & 1.414 .948 .576 \\
2011 & $\$$ & 1.226 .683 .303 & $\$$ & 358.289 .785 & $\$$ & 1.584 .973 .089 \\
2012 & $\$$ & 1.502 .917 .396 & $\$$ & 629.100 .103 & $\$$ & 2.132 .017 .499 \\
2013 & $\$$ & 1.542 .267 .668 & $\$$ & 695.689 .294 & $\$$ & 2.237 .956 .962 \\
2014 & $\$$ & 1.656 .909 .813 & $\$$ & 692.996 .160 & $\$$ & 2.349 .905 .973 \\
2015 & $\$$ & 1.643 .474 .365 & $\$$ & 692.924 .562 & $\$$ & 2.336 .398 .927 \\
2016 & $\$$ & 1.510 .382 .711 & $\$$ & 633.549 .640 & $\$$ & 2.143 .932 .350 \\
2017 & $\$$ & 1.545 .540 .454 & $\$$ & 606.579 .426 & $\$$ & 2.152 .119 .881 \\
2018 & $\$$ & 1.586 .347 .733 & $\$$ & 568.161 .024 & $\$$ & 2.154 .508 .757 \\
2019 & $\$$ & 1.530 .357 .312 & $\$$ & 550.919 .677 & $\$$ & 2.081 .276 .989 \\
2020 & $\$$ & 1.512 .772 .021 & $\$$ & 534.275 .776 & $\$$ & 2.047 .047 .796 \\
\hline \multicolumn{4}{c}{ Fuente: Ministerio de Economía y Finanzas, periodo $2010-2020$}
\end{tabular}

\subsection{Costo económico y social de la seguridad ciudadana en Ecuador}

La tabla 6 muestra el costo económico y social como porcentaje del PIB en Ecuador. En lo que respecta a los costos sociales, el costo más alto como porcentaje del PIB se sitúa en el año 2010 con el 0,038\%, mientras que el de seguridad privada correspondió a 2015 con el 0,98\%, pero para el Estado fue en el año 2012 con el 2.42\% PIB. En promedio se evidencia que el mayor costo de la inseguridad en Ecuador recae sobre el Estado, al representar el 2,15\%, PIB, luego le sigue el costo en prevención del sector privado con el $0.88 \%$ y finalmente los costos sociales que reprsentaron el $0.024 \%$ entre $2010-2020$.

Tabla 6

Costos totales de la seguridad ciudadana, como porcentaje del PIB

\begin{tabular}{ccccc}
\hline Año & Costos sociales & $\begin{array}{c}\text { Costos privados en } \\
\text { seguridad }\end{array}$ & $\begin{array}{c}\text { Costo por parte } \\
\text { del Gobierno }\end{array}$ & $\begin{array}{c}\text { Costo total de la } \\
\text { seguridad }\end{array}$ \\
\hline 2010 & $0,038 \%$ & $0,80 \%$ & $2,03 \%$ & $2,87 \%$ \\
2011 & $0,031 \%$ & $0,84 \%$ & $2,00 \%$ & $2,87 \%$ \\
2012 & $0,026 \%$ & $0,86 \%$ & $2,42 \%$ & $3,31 \%$ \\
2013 & $0,026 \%$ & $0,92 \%$ & $2,35 \%$ & $3,30 \%$ \\
2014 & $0,020 \%$ & $0,93 \%$ & $2,31 \%$ & $3,26 \%$ \\
2015 & $0,019 \%$ & $0,98 \%$ & $2,35 \%$ & $3,35 \%$ \\
2016 & $0,019 \%$ & $0,88 \%$ & $2,15 \%$ & $3,03 \%$ \\
2017 & $0,020 \%$ & $0,84 \%$ & $2,06 \%$ & $2,91 \%$ \\
2018 & $0,020 \%$ & $0,88 \%$ & $2,00 \%$ & $2,89 \%$ \\
2019 & $0,021 \%$ & $0,86 \%$ & $1,93 \%$ & $2,79 \%$ \\
2020 & $0,022 \%$ & $*$ & $2,07 \%$ & $2,09 \%$ \\
Costos promedios & & & & $\mathbf{3 , 0 5 \%}$ \\
como \% del PIB & $\mathbf{0 , 0 2 4 \%}$ & $\mathbf{0 , 8 8} \%$ & $\mathbf{2 , 1 5 \%}$ & \\
\hline
\end{tabular}

* Nota: Datos disponibles hasta 2019 (ver tabla 4), por ello, no se expresó en términos del PIB Fuente: Investigación de campo 


\subsection{Discusión}

El análisis correlacional realizado mostró una relación directa entre los niveles de pobreza por ingresos, desigualdad, y desempleo por edades (15 y 24 años) con los homicidios, mientras que al relacionar esta variable con la tasa de desempleo, la relación a pesar de ser positiva era menos fuerte. En este sentido, un estudio realizado en Ecuador en el que relacionaban el desempleo (años 2014-2016) y los índices delictivos para los años 2013-2015 con datos trimestrales, obtuvieron "una correlación de 71.56\%, entre el desempleo y los índices de delincuencia, un valor P de 2.86526E-19 menor al nivel de significancia del 5\%" (Carrera, Govea, Hurtado, \& Freire, 2019, pág. 292).

Según el BID (2017), para el año 2014 "el delito le cuesta un 3\% del Producto Interno Bruto (PIB) a los países de América Latina y el Caribe, con un límite inferior de 2,41\% y un límite superior del 3,55\%" (pág. 28). En el mismo estudio también se menciona que para el año 2014, el costo para Ecuador fue 3,35\% del PIB. La estimación realizada en el presente trabajo de investigación dio como resultado, que para ese mismo año el costo para Ecuador fue del 3,26\% del PIB. Por otra parte, el costo de la inseguridad para el año 2014 como porcentaje del PIB, para países como Alemania es del 1,34\%, para Canadá (1,37\%), Austria (1,76\%), Francia (1,87\%), Reino Unido (2,55\%) y Estados Unidos (2,75\%)" (BID, 2017). Mientras que en Latinoamérica " Honduras y El Salvador tienen los costos más altos con el 6,51\% y 6,16\% del PIB respectivamente, y los costos más bajos en la región, son para Uruguay con el 2,23\% del PIB y México 1,92\% del PIB" (BID, 2017, pág. 29).

En otras palabras, el costo de la inseguridad para Ecuador es superior a lo que gastaron los países del primer mundo, como Estados Unidos y Reino Unido, pero es muy inferior a los costos del crimen con relación a naciones como Honduras y El salvador. El costo promedio para el bienestar en Ecuador entre los años 2010-2018 representó el 3,09\% del PIB, es decir, el costo derivado del crimen fue superior individualmente "al gasto en salud del Estado con el 2,17\% y al gasto de protección social, el cual fue de 1,33\% entre 2010- 2018" (CEPAL, 2018).

\section{Conclusiones}

El análisis teórico presentado logró mostrar a la pobreza, la desigualdad, el desempleo, entre otros, como los elementos facilitadores del crimen y la delincuencia en una sociedad. Al realizar el análisis correlacional con el grupo de edades con los niveles más altos de desempleo (15 y 24 años), la pobreza por ingresos, la desigualdad, con los homicidios, se obtuvo una relación directa y fuerte en dichas correlaciones, es decir, que en la medida que aumente la pobreza al mismo tiempo aumentarán los crímenes. No obstante, al realizar la correlación entre la tasa de desempleo nacional y los homicidios, la relación era menos fuerte.

El deterioro de la seguridad ciudadana en Ecuador se está convirtiendo en un nudo crítico para la legitimidad del poder político por parte de los ciudadanos porque con los niveles delictivos del año 2018 , el $50 \%$ las personas estarían de acuerdo en que los militares tomen el poder. Por otra parte, en promedio, sólo el 43,26\% de las personas confiarían en la justicia, en el caso de ser víctima de la delincuencia; mientras que un 45\% sintió temor ante la posibilidad de ser víctima de la delincuencia entre 2010-2018.

En relación a la pérdida de bienestar generado por el crimen y la inseguridad, se estimó que el costo social y económico, representó en promedio para Ecuador un 3,05\% del PIB, en el período 2010-2020, el mayor costo es para el Estado con el 2,15\% del PIB, mientras que el costo en prevención para el sector privado es del $0.88 \%$ del PIB y finalmente el costo social significó el 0,024\% del PIB.

En definitiva, las políticas públicas implementadas por parte del Estado no han logrado hacer efectivo el derecho de las personas a disfrutar de un clima de paz y seguridad. Debido a que se han centrado por lo general, en tomar 
decisiones coyunturales, como el incremento del gasto público, y no estrategias estructurales, que permitan identificar las causas estructurales detrás de delincuencia, y en ese sentido, las consecuencias que éstas generan en el bienestar de las personas.

Por lo tanto, la respuesta del Estado ante esta problemática debería centrarse en diseñar políticas públicas que minimicen la pérdida social y económica, para el Ecuador, partiendo de un enfoque integral, que reduzcan todos aquellos incentivos a delinquir y que considere los efectos sobre las víctimas indirectas del crimen y la delincuencia.

\section{Referencias bibliográficas}

Abello, A., \& Pearce, J. (2007). De una Policía Centrada en el estado a una centrada en la comunidad. Lecciones del Intercambio entre las Policías Comunitarias de Bradford en el Reino Unido y de Medellín en Colombia. University of Bradford.

Abril, M., \& Tupiza, A. (2008). Delitos contra vehículos:el caso de Quito y Guayaquil. En J. Pontón, \& A. Santillán (Edits.), Nuevas problemáticas en seguridad ciudadana (Primera ed., Vol. III, págs. 63-78). Quito: FLACSO sede Ecuador.

ACNUR. (2017). Situación del triángulo Norte de Centroamérica. Alto Comisionado de las Naciones Unidas para los Refugiados(ACNUR), 9. Obtenido de https://www.acnur.org/fileadmin/Documentos/BDL/2017/11040.pdf

Arcos, C., Carrión Mena, F., \& Palomeque, E. (2003). Ecuador: informe de seguridad ciudadana y violencia 19901999. Quito: FLACSO, sede Ecuador. Obtenido de https://biblio.flacsoandes.edu.ec/shared/biblio_view.php?bibid=13060\&tab=opac

Arias, P. (2009). Seguridad privada en América Latina: el lucro y los dilemas de una regulación deficitaria. Santiago: FLACSO. Obtenido de https://flacsochile.org/biblioteca/pub/publicos/2009/libro/030857.pdf

Banco Mundial. (2011). Violence in the City:Understanding and Supporting Community Responses to Urban Violence. Washington, DC: Banco Mundial. Obtenido de https://documents1.worldbank.org/curated/en/524341468331181450/pdf/638880WPOViole00BOX36 1532B00public0.pdf

Baratta, A. (2004). Criminología crítica y crítica del derecho penal: Introducción a la sociología jurídico penal (Primera ed.). (Ä. Búnster, Trad.) Buenos Aires, Argentina: Siglo XXI Editores.

Becker, G. (1974). Crimen y castigo: un enfoque económico.

BID. (2017). Los costos del crimen y de la violencia: nueva evidencia y hallazgos en América Latina y el Caribe. (L. Jaitman, Ed.) BID. Obtenido de Banco Interamericano de Desarrollo: https://publications.iadb.org/es/publications/spanish/document/Los-costos-del-crimen-y-de-laviolencia-Nueva-evidencia-y-hallazgos-en-Am\%C3\%A9rica-Latina-y-el-Caribe.pdf

Carrera, F., Govea, F., Hurtado, G., \& Freire, C. (2019). Estudio correlacional de factores como índices de desempleo y delincuencia en Ecuador. Información tecnológica, XXX(3), 287-294. doi:http://dx.doi.org/10.4067/S0718-07642019000300287

Carrillo, J. (2018). Incidencia de femicidio en el Ecuador y en la provincia del Guayas. Universidad y Sociedad, $X(1), 125-133$. Obtenido de http://scielo.sld.cu/pdf/rus/v10n1/2218-3620-rus-10-01-125.pdf 
Carrión, A. (2012). El capital social en la resolución de conflictos y creación de desarrollo: el caso nicaragüense. Revista de Paz y Conflictos, V, 139-156. Obtenido de https://revistaseug.ugr.es/index.php/revpaz/article/view/470/549

CEPAL. (2018). Comisión Económica para América Latina y el Caribe. Obtenido de Comisión Económica para América Latina y el Caribe: https://observatoriosocial.cepal.org/inversion/es/paises/ecuador

CEPAL. (2019). Nudos críticos del desarrollo social inclusivo en América Latina y el Caribe: antecedentes para una agenda regional. Santiago: CEPAL. Obtenido de https://www.cepal.org/es/publicaciones/44799nudos-criticos-desarrollo-social-inclusivo-america-latina-caribe-antecedentes

Felson, M., \& Clarke, R. (2019). La ocasión hace al ladrón. Teoría práctica para la prevención del delito. En E. Tanner, S. Jo, M. Lipsey, M. Felson, R. Clarke, R. Sampson, ... An, D. Gorgal, \& A. Föhrig (Edits.), Seguridad ciudadana. Lecciones fundamentales (págs. 59-100). Caracas: CAF.

Giménez, G. (2007). Violence and Growth in Latin America. Economic Analysis Working Papers, VI(8), 1-34. Obtenido de http://www.unagaliciamoderna.com/eawp/coldata/upload/Violence\%20and\%20growth\%20in\%20latin \%20america.pdf

Hernández, H., \& Narro, J. (2010). El homicidio en México, 2000-2008. Papeles de Población, XVI(63), 243-271. Obtenido de https://www.redalyc.org/articulo.oa?id=11213201009

Larrauri, E. (2000). La herencia de la criminología crítica (Tercera ed.). Madrid, España: Siglo XXI Editores.

Libreros, J. (2001). Descentralización y orden público en Colombia. Revista Opera, I(1), 199-211. Obtenido de https://www.redalyc.org/articulo.oa?id=67510110

Loor, W., Hidalgo, H., Macías, J., García, E., \& Scrich, A. (2018). Causas de las adicciones en adolescentes y jóvenes en Ecuador. Revista Archivo Médico de Camagüey, XXII(2), 130-138. Obtenido de https://www.redalyc.org/journal/2111/211159713003/211159713003.pdf

Lunecke, A., \& Ruiz, J. (2007). Capital social y violencia: análisis para la intervención en barrios urbanos críticos. En L. Dammert, \& L. Zúñiga (Edits.), Seguridad y violencia: desafíos para la ciudadania (págs. 225-252). Santiago, Chile: FLACSO. Obtenido de https://biblio.flacsoandes.edu.ec/shared/biblio_view.php?bibid=107310\&tab=opac

Maldonado, C., Martínez Pizarro, J., \& Martínez, R. (2018). Protección social y migración: Una mirada desde las vulnerabilidades a lo largo del ciclo de la migración y de la vida de las personas. Santiago: CEPAL.

Merton, R. K. (1995). Teoría y estructura sociales. Fondo de Cultura Económica, 209-239.

Ministerio de Gobierno. (2019). Ministerio de Gobierno . Obtenido de Ministerio de Gobierno: http://cifras.ministeriodegobierno.gob.ec/comisioncifras/inicio.php

Ministerio de Gobierno. (2021). Informe de rendición de cuentas 2020. Ministerio de Gobierno. Obtenido de https://www.ministeriodegobierno.gob.ec/wp-content/uploads/2021/05/Acta-de-plenaria-2020.pdf

Noboa, G., Ruiz, K., Pazmiño, M., \& Vela, V. (2019). El sicariato un inconveniente social que aqueja a los adolescentes en el Ecuador. Revista De Investigación Enlace Universitario, XVIII(1), 48-57. doi:https://doi.org/10.33789/enlace.18.46 
OEA-PNUD. (2010). Nuestra Democracia. México: Fondo de Cultura Económica. Obtenido de https://www.oas.org/es/sap/docs/nuestra_dem_s.pdf

Park, R. (1999). La Ciudad y otros ensayos de ecología urbana. (E. Martínez, Trad.) Barcelona: Ediciones del Serbal. Obtenido de https://docplayer.es/169901-Robert-ezra-park-la-ciudad-y-otros-ensayos-deecologia-urbana-estudio-preliminar-y-traduccion-de-emilio-martinez-ediciones-delserbal.html\#show_full_text

Park, R. (2016). La organización de la comunidad y la delincuencia juvenil. Delito y Sociedad, 115-124.

Pazinato, E. (2020). Gobernanza y Gestión. En K. Villa, V. Vélez, B. Cedillo, A. Restrepo, P. Munguía, V. Vélez, B. Cedillo, A. Restrepo, \& A. Cabezón (Edits.), Líderes para la Gestión en Seguridad Ciudadana y Justicia (págs. 103-153). Banco Interamericano de Desarrollo (BID);Centro de Estudios en Seguridad Ciudadana (CESC)de la Universidad de Chile;John Jay College of Criminal Justice;Faculdade de Direito de Santa Maria (FADISMA).

Pérez, C., \& Navarrete, N. (2018). El sector de seguridad y vigilancia privada: evolución reciente y principales retos laborales, regulatorios y de supervisión. Bogotá: Fedesarrollo.

PNUD. (2013). Informe Regional de Desarrollo Humano 2013-2014 Seguridad Ciudadana con rostro humano:diagnóstico y propuestas. Nueva York: PNUD.

PNUD. (2019). Informe sobre Desarrollo Humano 2019. Más allá de los ingresos, más allá de los promedios, más allá de hoy: Desigualdades en el desarrollo humano en el siglo XXI. Nueva York: PNUD. Obtenido de http://hdr.undp.org/sites/default/files/hdr_2019_es.pdf

PNUD. (2020). Análisis sobre innovación en seguridad ciudadana y derechos humanos en América Latina y el Caribe.Una perspectiva desde las políticas públicas y la gestión institucional. PNUD.

Rivera, J. (2016). El deterioro del Capital Social como promotor de la violencia y la delincuencia entre la población del municipio de Rioverde, San Luis Potosí. Papeles de población, 103-132. Obtenido de https://rppoblacion.uaemex.mx/article/view/8288/6904

Robles, A. (2014). Miedo en las calles: principal emoción de la inseguridad pública delictiva.Un estudio criminológico y de género. Revista IUS, VIII(34), 81-100. Obtenido de http://www.scielo.org.mx/pdf/rius/v8n34/v8n34a6.pdf

Soria, R. (2017). El impacto de la inseguridad pública en la competitividad empresarial. Análisis comparativo de las entidades federativas en México. Economía y Sociedad, XXI(36), 19-41. Obtenido de https://www.redalyc.org/pdf/510/51052064002.pdf

Sutherland, E. (1999). El delito de cuello blanco. (F. Álvarez, Ed., \& R. Del Olmo, Trad.) Madrid, España: La piqueta.

Sutherland, E. (2016). Una exposición de la teoría. (A. Montero, Trad.) Delito y Sociedad, I(31), 119-122. doi:https://doi.org/10.14409/dys.v1i31.5637

Tanner, E., Jo, S., \& Lipsey, M. (2019). Factores de riesgo y crimen. En E. Tanner, S. Jo, M. Lipsey, M. Felson, R. Clarke, R. Sampson, ... R. Sampson, D. Gorgal, \& A. Föhrig (Edits.), Seguridad ciudadana. Lecturas fundamentales (B. d. CAF, Trad., págs. 29-58). Caracas: CAF. 
United States Department of State. (2020). International Narcotics Control Strategy Report. Bureau for International Narcotics and Law Enforcement Affairs. Obtenido de https://www.state.gov/wpcontent/uploads/2020/06/Tab-1-INCSR-Vol.-I-Final-for-Printing-1-29-20-508-4.pdf

UNODC. (2012). Informe Mundial sobre las Drogas 2012. Viena: UNODC. Obtenido de https://www.unodc.org/documents/data-and-analysis/WDR2012/WDR_2012_Spanish_web.pdf

UNODC. (2013). Estudio Mundial sobre el Homicidio 2013:Tendencias Contexto y datos. UNODC.

UNODC. (2014). Regulación por el Estado de los servicios de seguridad privada civil y contribución de esos servicios a la prevención del delito y la seguridad de la comunidad. Nueva York: UNODC. Obtenido de https://www.unodc.org/documents/congress//background-

information/Crime_Prevention/HB_on_private_security-Spanish.pdf

UNODC. (08 de 07 de 2019). La Oficina de las Naciones Unidas contra la Droga y el Delito. Obtenido de La Oficina de las Naciones Unidas contra la Droga y el Delito:

https://news.un.org/es/story/2019/07/1458941

Vuanello, R. (2009). Inseguridad urbana y sus efectos:percepción de los jóvenes. Revista Criminalidad, LI(2), 3346. Obtenido de http://www.scielo.org.co/pdf/crim/v51n2/v51n2a03.pdf

Zambrano, S. (2016). El acceso a la justicia y la tutela judicial efectiva en relación con la seguridad. DíKÊ.Revista de investigación en Derecho, Criminología y Consultoría, IX(39), 65-87. Obtenido de https://dialnet.unirioja.es/servlet/articulo?codigo $=6184320$

Zuleta, A. (2019). Análisis del femicidio: tipificación y realidades en el Ecuador. Revista científica Ecociencia, VI, 1-19. Obtenido de http://revistas.ecotec.edu.ec/index.php/ecociencia/article/view/247/192

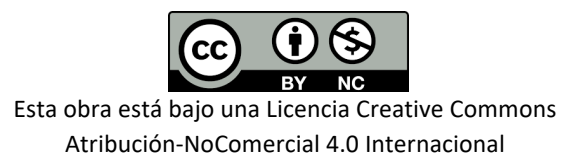

